\title{
Possibilities of Using Tram Windscreen Impact Tests in Analysis of Human-Machine Acci- dents
}

\author{
Václav Bittner ${ }^{1,3}$, Roman Ježdík ${ }^{2}$, Petr Kubový ${ }^{1}$, František Lopot ${ }^{1}$, Ondřej Štoček ${ }^{1}$, Martin Havlíček $^{1}$, Martin Svoboda $^{4}$, \\ Karel Jelen ${ }^{1}$ \\ ${ }^{1}$ Faculty of Physical Education and Sport, Charles University in Prague, José Martího 31, Prague 6, Czech Republic. E- \\ mail: kubovy@ftvs.cuni.cz, jelen@ftvs.cuni.cz, ondrastok@seznam.cz, martin.h2@seznam.cz \\ ${ }^{2}$ Research Institute of Railway Rolling Stock - VÚKV a.s., Bucharova 1314/8 Stodůlky, Prague 5, Czech Republic. E- \\ mail: jezdik@vukv.cz \\ ${ }^{3}$ Faculty of Science, Humanities and Education, Technical University of Liberec, Studentská 2, Liberec, Czech Republic. \\ E-mail: vaclav.bittner@tul.cz \\ ${ }^{4}$ Faculty of Mechanical Engineering, J. E. Purkyně University in Ústí nad Labem, Pasteurova 1, Ústí nad Labem, Czech \\ Republic. E-mail: martin.svoboda@ujep.cz
}

The main aim of this article is to show the possibilities of using tram windscreen impact tests in the analysis of human-machine accidents. Empirical experience shows that these accidents especially affect the head, which is at the same time one of the most vulnerable parts of the human body. Windscreen safety testing follows ECE standards and, inter alia, involves collisions with a headform. With regards to numerical simulations, however, it is essential to be able to determine the material characteristics of windscreens. Here it seems to be advantageous in terms of validity, reliability and the economic cost of using collisions with a rigid body where only the glass absorbs all of the kinetic collision energy. The outcome of these tests is a waveform of the contact force's magnitude as a function of deformation in the direction the force acts. Along with the time course of acceleration of the bumper and its kinetic energy on impact, this information can serve as boundary conditions to verify mathematical models.

Keywords: impact tests; human-machine accidents; tram; windscreen

\section{Introduction}

The analysis of rolling stock accidents associated with pedestrian safety has become more and more important in recent years. This is due to the increasing density of tram traffic in the centre of large cities and the associated risk of human-machine collisions. Table 1 shows that only 561 pedestrian collisions with trams have occurred in the capital city of Prague over the past 5 years. Of these, approximately $5 \%$ were fatal. Collisions of trams with pedestrians most commonly result from [1]: not giving way to a tram at a pedestrian crossing, crossing just in front of the tram (the driver often has no chance to see the pedestrian), looking in front of a tram in an attempt to run over to the pavement (a train may come from the opposition), entering the path of a starting tram (incorrect estimation of tram stopping distance), using headphones and mobile phones.

Tab. 1 Variations of acceleration measurements performed on the vehicle

\begin{tabular}{|c|c|c|}
\hline Year & Number of collisions & Number of deaths *) \\
\hline 2013 & 82 & 6 \\
\hline 2014 & 90 & 4 \\
\hline 2015 & 99 & 4 \\
\hline 2016 & 75 & 2 \\
\hline 2017 & 111 & 3 \\
\hline 2018 & 104 & 8 \\
\hline
\end{tabular}

*) Number of accidental deaths that occurred within 24 hours of a collision. The actual number of subsequent deaths could be higher.

Source: processed according to [1]

Modern city trams have the lower edge of their windscreens usually below the level of an adult's shoulders, so they collide with the pedestrian's head very often during collision. At a high collision velocity, the contact points of such a collision on the tram windscreen are noticeable and take on characteristic contours (see Fig. 1). For obvious reasons, it is appropriate to study these collision events and investigate the mechanical properties of windscreens. Their manufacturer is obliged to perform stress tests following the ECE regulation [2]. There is a headform impact test with an integrated accelerometer within the scope of this piece of legislation. In this case, it is obvious that the impactor accelerations are affected by the rigidity of the headform and how it is affixed. It is necessary to take this fact into account when estimating the results of collision processes. An alternative approach is to use a rigid impactor (battering ram) on glass adequately fixed in place. In these tests, it is assumed that the impactor is perfectly rigid and that all the collision's kinetic energy is absorbed by the glass. This article aims to show the possibilities of using such tram windscreen impact tests in the analysis of human-machine accidents. The first part presents a brief summary of the theoretical background. The second part of the paper demonstrates the results of the pilot experimental investigation. 


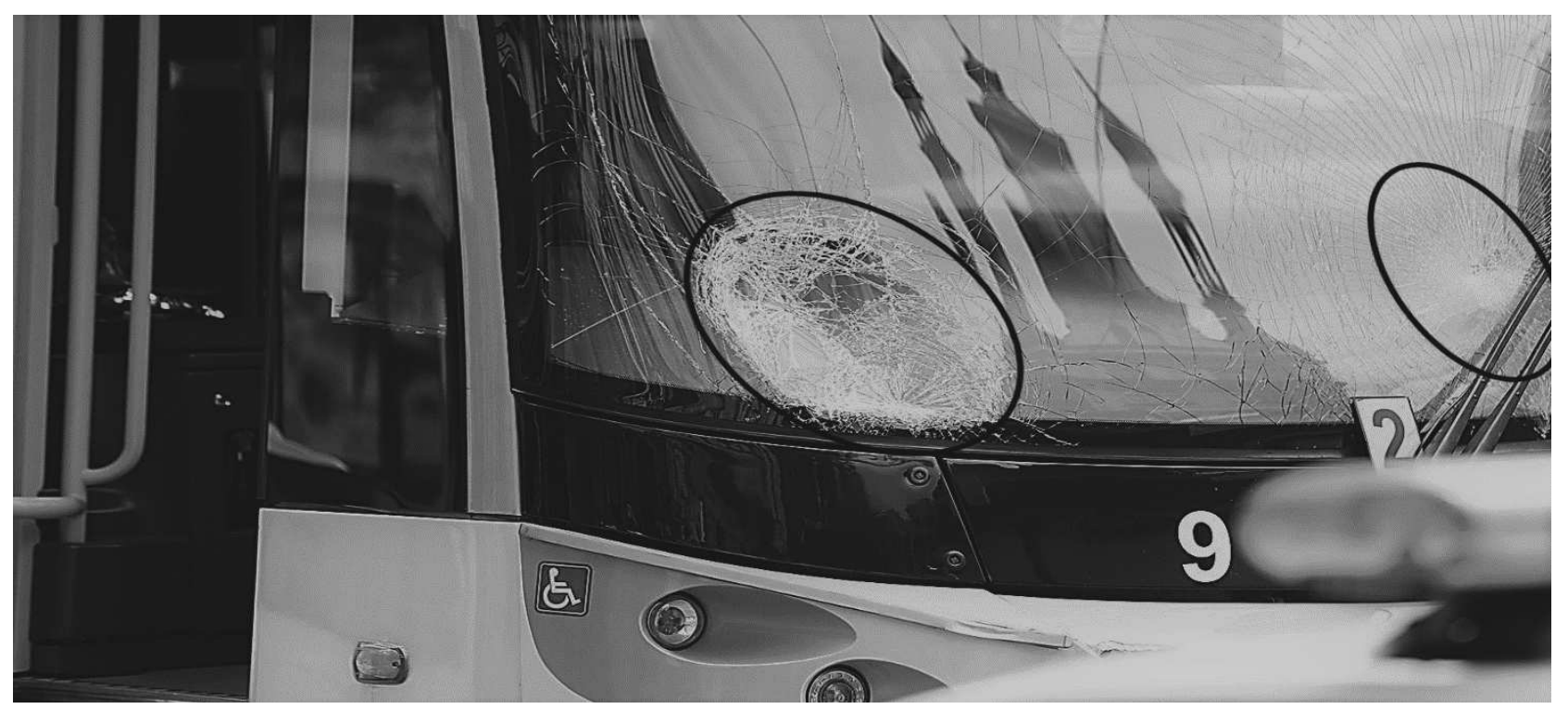

Fig. 1 Tram windscreen after a collision with two pedestrians - contact points Source: taken from [6] (photo by Michal Šula, MAFRA)

\section{Selected Theoretical Bases}

Collision processes between humans and machines have been widely studied, especially in the automotive industry. Virtual modelling and numerical simulation are the most frequently used methods in addressing pedestrian safety [4]. For these simulations to be valid, it is necessary to verify the models against real data from impact tests. For this purpose, collisions of vehicles or their parts (e.g. windscreens) with solid models of the body, called an ATD (anthropomorphic test device), and its parts are used. Head, chest and knees are among the most vulnerable parts of the human body [4]. The general HIC criterion is used to estimate the injury rate. This can be calculated from the time course of acceleration $a(t)$ of the centre of gravity of the monitored part during the impact test using the formula:

$$
H I C_{t_{2}-t_{1}}=\max _{0 \leq t_{1}<t_{2} \leq T}\left\{\left(t_{2}-t_{1}\right)\left(\frac{1}{t_{2}-t_{1}} \int_{t_{1}}^{t_{2}} a(t) d t\right)^{2.5}\right\}
$$

where $t_{2}$ and $t_{1}$ are two arbitrary times during the acceleration pulse [4]. The acceleration $a(t)$ in the formula (1) is given in multiples of $g=9.81 \mathrm{~ms}^{-2}$. In the automotive industry, $\mathrm{HIC15} \equiv \mathrm{HIC}_{0.015}<700$ is considered to be an acceptable risk for head-to-vehicle collisions where the risk of brain injury is less than $5 \%$ [8].

If a rigid impactor is used instead of the ATD head, the calculated HIC is only the supremum of the estimation of this criterion. On the other hand, the situation will be considerably simplified. From the results of such tests, it is then relatively easy to obtain a working diagram of the impact test, i.e. the dependence of the contact force between the two bodies on the displacement in the direction of the force acts (see below). The material properties of windscreens can also be estimated based on a suitable physical model. Both can then be used to create numerical models, etc.
From a mechanical point of view, if a rigid, for example, oval body strikes the flat surface of a windscreen, a contact stress occurs at the point of contact. Because the windscreen is in the shape of a shell, bending stresses will also occur throughout its surface. The total accumulated energy is then equal to the sum of the bending and contact stresses of the glass [3]. This energy $E_{\text {cum }}$ can be estimated from the velocity $v_{d}$ and the weight $m_{d}$ of the impactor according to the formula:

$$
E_{\text {cum }}=\frac{1}{2} m_{d} v_{d}^{2}=\int_{0}^{z_{\max }} F_{c}(z, t) d z
$$

It can be seen from the equation (2) that the accumulated energy can be estimated from the waveform of the surface contact force $F_{c}(z, t)$ depending on the displacement of the material points near the point of contact. The direction of the displacement, as well as the direction of the contact force, are directed perpendicular to the plane of the glass (along the $z$-axis). The magnitude of the contact force can be determined from the time course of acceleration $a(z, t)$ recorded by an accelerometer placed on the rigid impactor according to the formula:

$$
F(z, t)=m_{d} a(z, t)
$$

The displacement size $z(t)$ can be determined experimentally by a displacement meter located under the windscreen at the point of impact of the impactor (see Figure 3).

Fracture deformations may be expected to occur during impact tests of vehicle windscreens. Their shape will largely depend on the speed of the impactor. In a quasi-static case where the impact velocity of the impactor is low (lower values of $\mathrm{m} / \mathrm{s}$ ), the fracture stress will be achieved by the bending process. The result will be the specific shape of fracture cracks (see Fig. 2a), 
identical to the static stress [3]. If the velocity of the impactor is higher (higher values, tens of $\mathrm{m} / \mathrm{s}$ ), the inertia forces will hinder the rapid deflection of the plate. This will result in a greater curvature of the deflection surface near the contact point than in the wider surroundings, resulting in differently shaped fracture cracks (see Fig. 2b), different from the previous example [3]. If the impact velocity is high (hundreds of $\mathrm{m} / \mathrm{s}$ ), before the glass plate starts to deflect, the contact stress increases to such a limit that a radiating crack occurs (see Fig. 2c) [3].
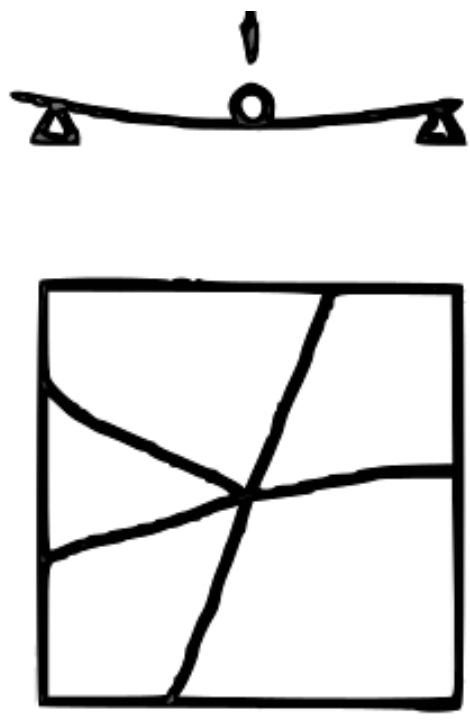

a
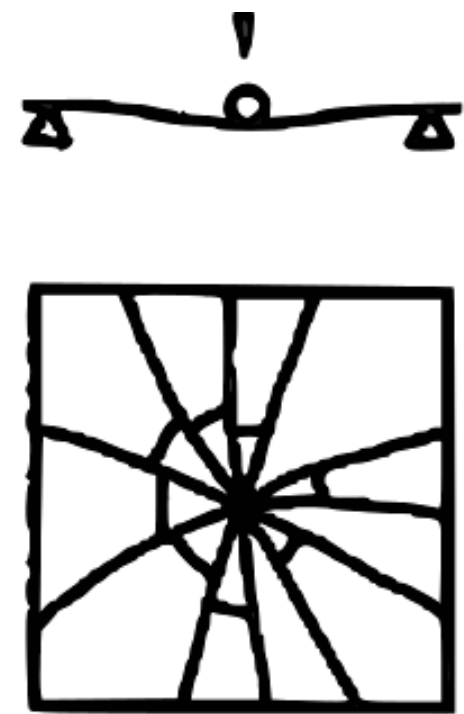

b
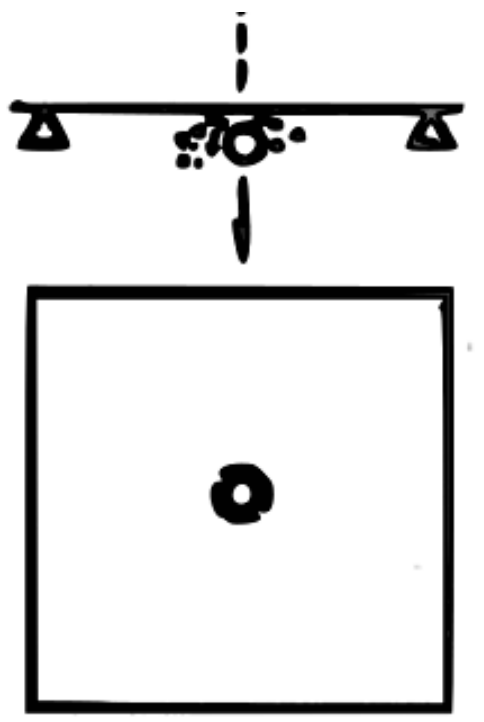

C

Fig. 2 Fracture of glass plates at different intensity of impact from a rigid impactor. Source: taken from [3]

In relation to the equation (3) and the determination of the magnitude of the contact force, the question arises as how to choose the mass of the impactor. As already mentioned in the introduction of the article, it is usually the head that hits the windscreen of a tram. One can therefore start from the estimated mass of the human head $m_{h}$. This can be determined according to [5] the following equation:

$$
\begin{aligned}
& m_{h}=B_{0}+B_{1} m+B_{2} v \\
& m_{h}=1,296+0,0171 m+0,0143 v
\end{aligned}
$$

where the symbols $B_{i}, i \in\{0,1,2\}$ represent constants obtained from [5]; $m$ is the total body mass [ $k g]$, and $v$ the body height $[\mathrm{cm}]$. It is therefore a linear function of two variables, producing a graph that is generally a plane. Thus, the absolute extremes of such a function will lie at the boundaries of the set delimited by the Cartesian product of two intervals for $m$ and $v$. Assuming that an adult height $v$ is within the interval $[160 ; 200] \mathrm{cm}$ and his/her body mass $m$ is in the interval $[55 ; 110] \mathrm{kg}$, based on the formula (4), the head mass $m_{h}$ can be expected to be in the range of $4.5-6 \mathrm{~kg}$.

\section{Experimental Methods}

Windscreen impact tests were carried out on a drop weight impact tester in the VÚKV testing laboratory (see Fig. 3). Each sample (6.76 $\mathrm{mm}$ thick laminated windshield, dimensions $500 \mathrm{~mm} \mathrm{x} 300 \mathrm{~mm}$ ) was supported near the edges by a solid steel support frame.
Because the samples were slightly curved, a special support frame was prepared for each sample by scanning the sample surface. A potentiometric displacement sensor was mounted below the centre of the sample. A highspeed camera was installed in front of the tester to detect the breakage of the glass.

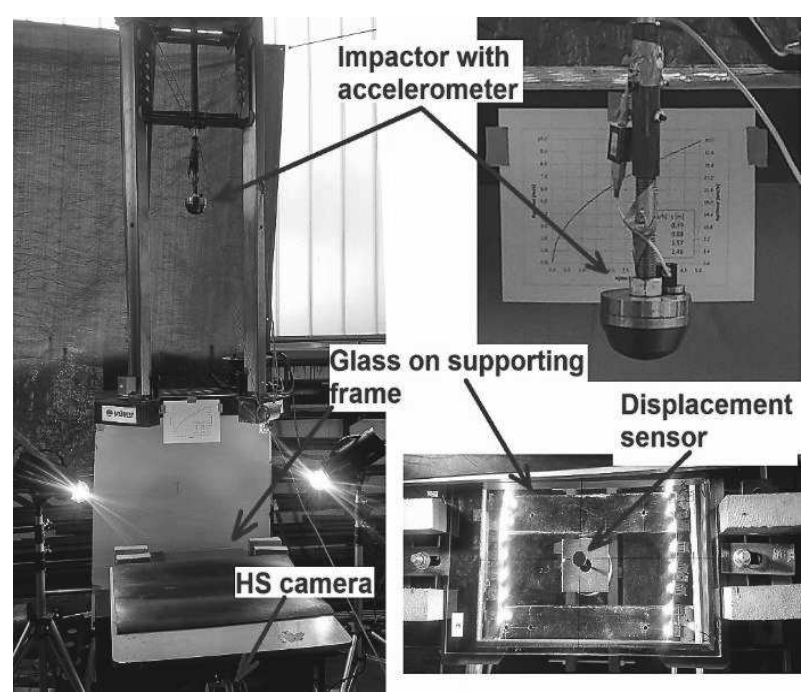

Fig. 3 Example of measuring apparatus.

The impactor (battering ram) in question consisted of a head, a ring and a threaded rod. It was also fitted with an accelerometer. The impactor mass was selected within the technical limits, based on an estimate from the equation (1) and taking into account the characteristics of the ATDs. It was set to $4.55 \mathrm{~kg}$. 


\section{Results and Discussion}

Pilot tests were performed on one glass sample for two different impact velocities not exceeding the $25 \mathrm{~km} / \mathrm{h}$ limit. The working diagrams (force-displacement) are given for an impact velocity of $24.1 \mathrm{~km} / \mathrm{h}$ and $19.3 \mathrm{~km} / \mathrm{h}$ in Figure 5. The force magnitude was obtained as a product of the impactor mass and filtered acceleration [7] (equation 3). The time recording of the original data from the accelerometer together with the waveform of the filtered signal is shown in Figure 4. The graph of acceleration versus time (see Fig. 4) clearly shows the oscillations resulting from the excited transverse oscillations of the whole system. In the same graph, a thin dashed line indicates the method for estimating the HIC0.015 upper limit. After inserting the values from Figure 4 into the equation (1), the following can be written for the impact velocity of the impactor $v_{1}=19.3 \mathrm{~km} / \mathrm{h}$ :

$$
H I C 15 \leq H I C_{0.015}^{\text {sup }}=0.015\left(\frac{1074 \cdot 0.00085+770 \cdot 0.00135+1000 \cdot 0.005+450 \cdot 0.0078}{9.81 \cdot 0.015}\right)^{2.5}<640
$$

The upper limit of $H I C_{0.015}^{\text {sup }}<661$ for the impactor impact velocity $v_{2}=24.1 \mathrm{~km} / \mathrm{h}$ was estimated in the same way. Both values are below the critical limit of 700. It can therefore be assumed that the consequences of such headto-windscreen contact will certainly be serious but would not have to be fatal. The question is whether a skull would crack upon such an impact.

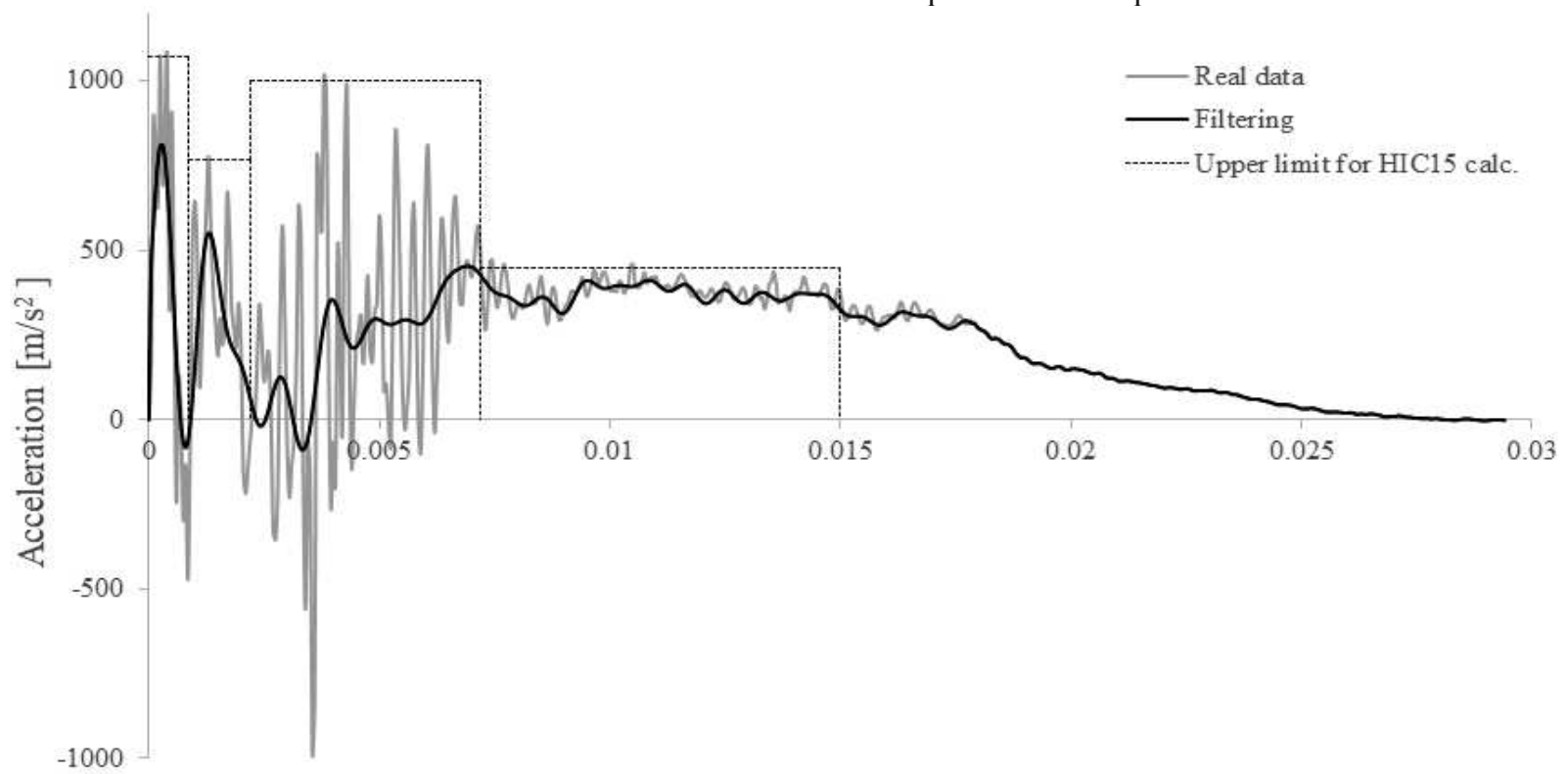

Time $[\mathrm{s}]$

Fig. 4 Waveform of the impact test-graph of impactor acceleration versus time (impact velocity $19.3 \mathrm{~km} / \mathrm{h}$ ).

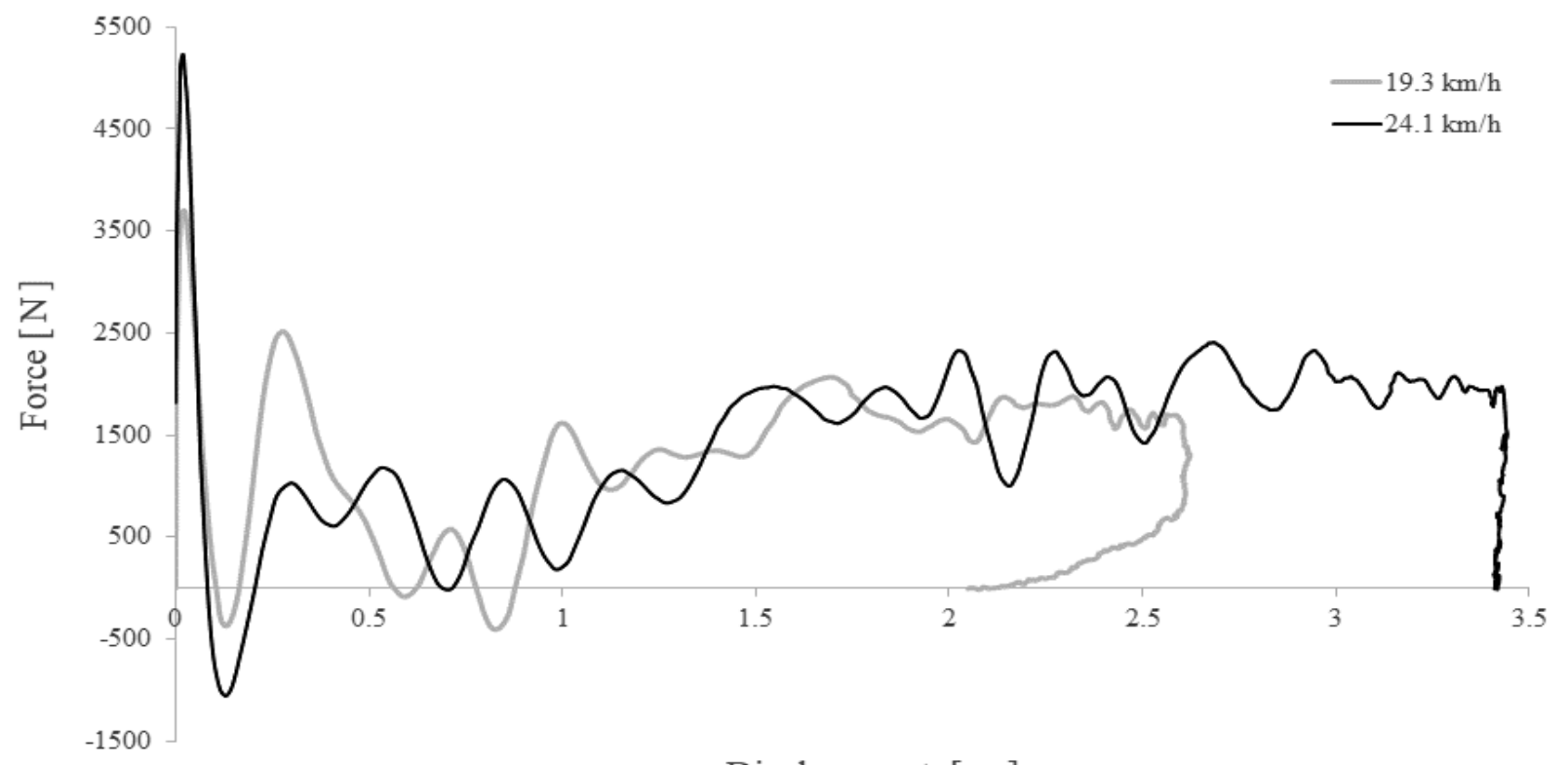

Displacement $[\mathrm{cm}]$

Fig. 5 Waveform of the impact test-graph of contact force versus displacement (working diagram) for impactor impact velocities of 19.3 and $21.4 \mathrm{~km} / \mathrm{h}$. 
It is very clear from the graph in Figure 5 how the collision took place. Consistent with the theoretical bases, within the small deformations, instantaneous contact stress occurred directly at the point of contact of both bodies. Their low compressibility resulted in a steep increase in contact force. Fracture plastic deformation occurred in the glass samples as the battering ram impact continued. These also resulted in a short-term drop in contact force. Furthermore, the movement of the impactor continued up to the limit displacement. Its kinetic energy was completely absorbed by plastic deformations in it.

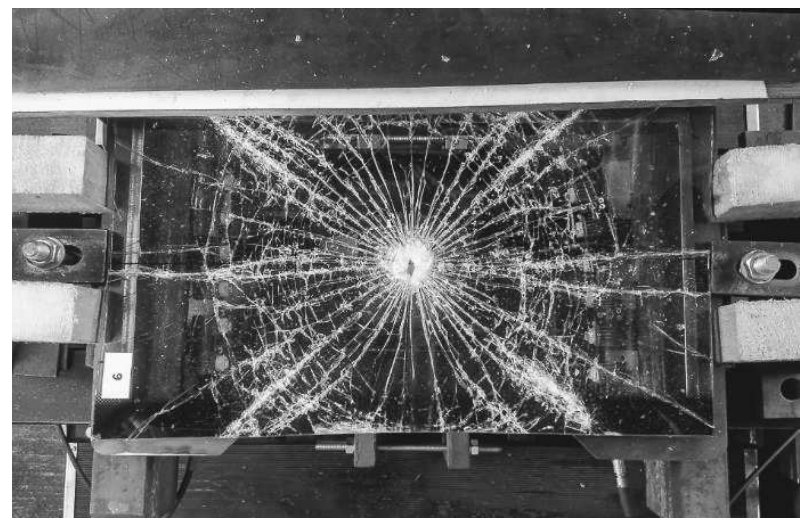

Fig. 6 Demonstration of fracture cracks during tram windscreen impact test.

Fracture cracks occurred in the glass during impact (see Fig. 6). Their shape and appearance correspond both to the theory described (see Fig. 3b) and to the real-life case of a pedestrian collision with the tram windscreen (see Fig. 1).

\section{Conclusion}

The aim of the article has been to show the possibilities of using tram windscreen impact tests in the analysis of human-machine accidents. The selected theoretical bases of this issue and pilot experimental investigation aimed at obtaining a working diagram of the impact test have been presented.

The results obtained can be used to estimate material properties of windscreens and for subsequent numerical simulations based on a suitably selected physical model. The work will continue to build just this theory. With regards to experimental methods, there is a link to the testing of windshield safety in original conditions on a real tram.

\section{Acknowledgments}

Supported from the Analysis of Pedestrian-Tram Accidents project - validation of simulation models, reg. No. CZ.02.1.01/0.0/0.0/16_026/0008401.

\section{References}

[1] Neskákej mi pod kola [online], 2019. EU: DPP [cit. 2019-06-11]. Available at: http://www.dpp.cz/neskakej-mi-pod-kolastartuje-bezpecnostni-kampan-na-prevencisrazek-tramvaji-s-chodci/.

[2] Legislativa ECE [online], 2014. EU [cit. 2019-0611]. Available at: https://eur-lex.europa.eu/legalcontent/EN/TXT/?uri=CELEX\%3A42014X0212\%2 $801 \% 29$.

[3] MENČÍK, J. (2018). Rázy a vibrace: základy mechaniky a zmírňování účinků. Pardubice: Univerzita Pardubice. ISBN 978-80-7560-146-9.

[4] HYNČÍK, L., KOCKOVÁ, H., ČÍHALOVÁ, L., CIMRMAN, R. (2008). Optimization of tram face with respect to passive safety. Applied and Computational Mechanics, 2008, roč. 2, č. 1, s. 53-62. ISSN: 1802-680X.

[5] ZACIORSKIJ, V. M., ARUIN, A. S., \& SELUJANOV, V. N. (1981). Biomechanics of the locomotor apparatus of man. 1981. Moskva: FiS.

[6] iDNES [online], 2018. Praha [cit. 2019-06-11]. Available at: [6] https:/www.idnes.cz/praha/zpravy/praha-chodci-tramvajsrazka-policie-uzavrela-pripad.A181219 _111633_praha-zpravy_nuc.

[7] BITTNER, V., TUČEK, R., PANSKÁ, ড̌., SVOBODA, M., JELEN, K. (2017). Using the fourier transform in the analysis of vibration load tests of heterogeneous mechanical systems. Manufacturing Technology. 17(6), 836-841. ISSN 1213-2489.

[8] MERTZ, H.J., PRASAD, P. and IRWIN, N.L. (1997). Injury risk curves for children and adults in frontal and rear collisions (SAE 973318). Proceedings of the 41st Stapp Car Crash Conference (P-315), 13-30. Warrendale, PA: Society of Automotive Engineers. 